\title{
Care for Patients with Chronic Nonmalignant Pain with and without Chronic Opioid Prescriptions: A Report from the Cincinnati Area Research Group (CARinG) Network
}

\author{
Nancy C. Elder, MD, MSPH, Todd Simmons, BS, Saundra Regan, PhD, \\ and Erica Gerrety, BS
}

Background: The use of chronic opioids for patients with chronic nonmalignant pain (CNMP) is a common problem for family physicians, yet little is known about the management of CNMP in family medicine offices.

Methods: Twenty one physicians at 8 practices of the Cincinnati Area Research Group (CARinG) network completed 25 to 30 modified Primary Care Network Survey 2 surveys. Each survey contained the question, "To your knowledge, does this patient have chronic (>3 months) pain, even if they are not being seen for pain today?" Chart reviews of all patients identified as having chronic pain were performed to examine assessment, management, and monitoring of chronic opioids. Ten of these physicians and 10 office nurses or medical assistants were interviewed about caring for patients with chronic pain.

Results: Primary Care Network Survey 2 questionnaires were completed for 533 patients, 138 (26\%) of which had CNMP, and 65 (47\%) of those were taking chronic opioids; $25 \%$ of patients taking chronic opioids had a urine drug screen and $22 \%$ had an opioid contract in the chart. Patients with CNMP who were taking chronic opioids were more likely to be younger ( 54 vs 59 years; $P=.003$ ), have a coexisting mental health diagnosis $(69 \%$ vs $44 \% ; P=.005)$, and have assessments for pain $(P=.031)$, function $(P=.003)$, and psychological distress $(P<.001)$ and a second opinion $(P=.001)$ in the chart than did patients with CNMP who were not taking opioids. Physicians described suspicion of patients as a primary difficulty in prescribing or considering chronic opioids; they also expressed interest in practicing evidence-based CNMP care, but there was little teamwork between physicians and medical assistants caring for patients with CNMP who were taking chronic opioids.

Conclusions: Chronic opioids are frequently prescribed to patients with CNMP. Although patients taking opioids have better documentation of pain assessments and management, care for all patients with CNMP fell short of evidence-based guidelines and was primarily performed by the physician alone. (J Am Board Fam Med 2012;25:652-660.)

Keywords: Chronic Disease, Pain Management, Practice-based Research, Practice-based Research Networks

Chronic nonmalignant pain (CNMP) is pain caused by injury or disease that persists longer

This article was externally peer reviewed.

Submitted 22 February 2012; revised 30 May 2012; accepted 5 June 2012.

From the Department of Family and Community Medicine (NCE, SR), College of Nursing, University of Cincinnati (EG), Cincinnati, OH; and Department of Zoology, Miami University, Oxford, OH (TS).

Funding: The project described was supported by the National Center for Research Resources and the National Center for Advancing Translational Sciences, National Institutes of Health, through Grant 8 UL1 TR000077-04.

Conflict of interest: none declared than 3 to 6 months or longer than expected. ${ }^{1}$ In its report "Relieving Pain in America," the Institute of Medicine notes that, "Chronic pain has a distinct pathology, causing changes throughout the nervous system that often worsen over time. It has significant psychological and cognitive cor-

Disclaimer: The contents of this article are solely the responsibility of the authors and do not necessarily represent the official views of the National Institutes of Health.

Corresponding author: Nancy C. Elder, MD, MSPH, Department of Family Medicine, University of Cincinnati, PO Box 670582, Cincinnati, OH 45267 (E-mail: Nancy.Elder@uc.edu). 
relates and can constitute a serious, separate disease entity." 2 CNMP is particularly common in primary care settings, with prevalence estimated anywhere from $5 \%$ to $50 \%$, depending on the source. ${ }^{2-7}$ In alignment with the patient centered medical home (PCMH) and Chronic Care Model, ${ }^{8}$ many experts and clinicians agree that CNMP requires a multimodal, interdisciplinary approach to achieve maximum benefit for patients. ${ }^{2,9}$ CNMP, however, differs from many other chronic diseases cared for by primary care providers (PCPs) because of the availability of chronic opioids as a treatment option. PCPs must consider addiction, drug diversion, overdose, and legal and regulatory factors in their patient assessment and treatment decision making. ${ }^{10,11}$ For many providers, decisions about the use and management of chronic opioids remain one of the most difficult aspects of caring for patients with CNMP. ${ }^{12}$

Use of opioids to treat CNMP is complicated because there is limited evidence for their longterm effectiveness in reducing pain or increasing quality of life in patients with chronic pain, ${ }^{1}$ while increasing reports of overdoses and deaths ${ }^{13}$ have led to controversies about opioids' usefulness and safety. ${ }^{14-16}$ Despite this, opioids have become an increasingly common way to treat CNMP. From 1997 to 2006 there was a $327 \%$ increase in therapeutic opioid use. ${ }^{1}$

Several recent studies have confirmed that primary care physicians feel unprepared and uncomfortable managing CNMP, ,9,17-20 especially with regard to the management of chronic opioids. ${ }^{1,15,20,21}$ There are fewer data describing PCPs' actual prescription of opioids for CNMP. ${ }^{3}$ There are no studies comparing primary care management of patients with CNMP who are prescribed opioids with those who are not prescribed opioids. In fact, some studies define CNMP by the provision of opioids ${ }^{17,22,23}$ or compare those taking opioids not to other patients with CNMP, but to patients with no chronic pain. ${ }^{23}$ Still other studies looked only at specific populations, such as the homeless or substance abusers. ${ }^{24-26} \mathrm{We}$ sought to better understand the primary care management of patients with CNMP, especially the differences between those prescribed opioids and those not prescribed opioids, via chart reviews and in-depth interviews with family medicine physicians and office medical assistants. By better understanding this important distinction in the management of pa- tients with CNMP, practice-based interventions and quality improvement initiatives can be developed to assist providers with improving their care of patients with CNMP.

\section{Methods}

The Cincinnati Area Research Group (CARinG) Network is a regional network of family medicine physicians and nurse practitioners in the greater Cincinnati, Ohio, area. Founded in 2009, the CARinG Network includes 2 family medicine residencies as well as physicians in independent practices and practices belonging to 2 large health networks. At the time of the study, there were 10 member practices. This study received approval from the University of Cincinnati Institutional Review Board.

\section{Participants}

All 30 physician and nurse practitioner members of the CARinG Network were contacted by E-mail and phone to assess interest in participating in a practice-based survey study of chronic pain assessment and management. Twenty-one physicians at 8 practices agreed to participate; resident physicians were not included. Interviews then were performed with a subset of 1 or 2 physicians at each office and separately with a nurse or medical assistant (MA) who worked regularly with that physician. At the 6 offices with more than 1 physician, participants were purposefully chosen to include a range of demographic variables that might impact patient care, including sex, years of experience, and race. $^{27,28}$ At 2 of the larger practices ( $>4$ physicians), 2 physicians and MAs at each practice were asked to participate.

\section{Data Collection/Measures}

Each of the 21 physicians completed a modified Primary Care Network Survey 2 (PRINS-2) ${ }^{29}$ for each patient they saw until they completed 25 to 30 surveys each. Physicians were allowed to choose on which half days to complete the surveys. The PRINS-2 survey is a 1-page instrument with 19 items designed to characterize the clinician-patient encounter (patient demographics, clinical relationships, sources of payment, and the visit itself). ${ }^{29} \mathrm{We}$ modified the PRINS-2 by removing 6 questions (2 about payment, 4 about the visit) and adding 2 questions for this study: "To your knowledge, does this patient have chronic ( $>3$ months) pain, even if 
they are not being seen for pain today?" and "To your knowledge, does this patient have a mental health diagnosis (depression, anxiety, bipolar, etc.)?" If the physician marked "yes," to the chronic pain query, he or she then added the patient's name and date of birth to the survey. All other surveys had no patient identifiers.

Chart reviews were performed for each patient identified as having chronic pain. Because of logistic constraints, we only reviewed current charts. For example, if a patient had more than one paper chart, only the current chart was reviewed. In practices with electronic medical records (EMRs), only the EMR charts were reviewed, not an original paper chart (if one existed). EMRs had been in place at all study practices 2 years or longer. The chart review assessed details about the type of chronic pain(s), assessments of pain, disability and psychological distress, and management, including medications and nonpharmacological modalities. For patients taking opioids, further data were collected about patient contracts, urine drug screens, and state prescribing reports.

Interviews were semistructured and included a general opening question asking each participant to describe caring for a recent patient with chronic pain. Physicians were then asked general questions about caring for patients with CNMP and then to give specifics about various components of assessment, management, and office teamwork regarding CNMP care; they also were asked about prescribing opioids for chronic pain. MAs also were asked general questions about caring for patients with CNMP and then more specific questions about their role in assessment, management, and office teamwork.

\section{Data Analysis}

PRINS-2 and chart review data were entered into a database and statistical analyses were performed with SPSS version 19 (IBM/SPSS, Inc., Chicago, IL). For this study, we compared patient characteristics and pain management between those with CNMP who were and were not prescribed chronic opioids using $t$ tests and $\chi^{2}$ analyses. We also described and assessed the presence of chronic opioid management as recommended by evidence-based practice guidelines and Ohio state law. ${ }^{30-33}$

Interviews were transcribed and entered into NVivo 8 qualitative software (QSR International, Pty LTD., Australia) for analysis. Each transcript was read by at least 2 team members, with $10 \%$ of the interviews read by 3 team members (NCE, TS, EG). Group discussions focused on key categories that were found within the data themselves (the editing method) $)^{34,35}$ and then each interview was coded by one of 2 team members (NCE or EG), with $10 \%$ of the interviews coded by both analysts. The comments and codes relating to the use of chronic opioids were then reviewed in light of the quantitative findings, and a framework for understanding chronic opioids for the management of chronic pain in the CARinG Network was developed.

\section{Results}

Twenty-one family physicians in 8 practices completed the PRINS-2 for 533 patient visits. Ten of these physicians and 10 staff (8 MAs, 1 licensed practical nurse, and 1 registered nurse) were interviewed. Demographic details about the participants and their offices are found in Tables 1 and 2 .

Of the 533 patient visits recorded by the physicians on the modified PRINS-2, all were unique patients. The physicians identified 138 patients (26\%) as having chronic pain. However, chart reviews could only be performed on 137 patients because 1 paper chart was missing during the review period. Of those 137 patients, 65 (47\%) were currently taking chronic opioids. There were 16 charts that had a documented urine drug screen and 14 with a narcotic use contract $(25 \%$ and $22 \%$, respectively, of those patients taking chronic opioids). No charts documented that a state prescribing report had been obtained.

\section{Comparisons of Patients Taking Chronic Opioids with Those Not Taking Opioids}

Patients prescribed chronic opioids for their pain were significantly younger than those not taking opioids $(P=.003$; Table 3$)$. No differences existed between groups with regard to race and sex. Musculoskeletal pain (eg, knee pain, back pain) was the most common type in both groups, with osteoarthritis second in the nonopioid group and third in the opioid group. Although it is likely that a component of the musculoskeletal pains were caused by osteoarthritis, unless this was explicitly stated ("knee pain secondary to osteoarthritis"), if both osteoarthritis and musculoskeletal pains were documented within a chart, we counted them as 2 types of pain. 
Table 1. Participating Practices in the Cincinnati Area Research Group (CARinG) Network

\begin{tabular}{|c|c|c|c|c|c|c|}
\hline Site & $\begin{array}{l}\text { Participating Physicians } \\
\text { in Practice }(\mathrm{n}=21)\end{array}$ & $\begin{array}{l}\text { Total Physicians in } \\
\text { Practice }(\mathrm{n}=30)\end{array}$ & $\begin{array}{c}\text { Electronic } \\
\text { Medical Record }\end{array}$ & $\begin{array}{l}\text { Geographic } \\
\text { Location }\end{array}$ & Type of Practice & $\begin{array}{c}\text { PRINS-2 Surveys } \\
\text { Completed }(\mathrm{N}=533)\end{array}$ \\
\hline 1 & 4 & 7 & Yes & Suburban & University affiliated & 98 \\
\hline 2 & 4 & 5 & Yes & Rural & Residency & 104 \\
\hline 3 & 2 & 2 & Yes & Suburban & University affiliated & 46 \\
\hline 4 & 2 & 3 & Yes & Urban & $\begin{array}{l}\text { Local hospital } \\
\text { affiliated }\end{array}$ & 40 \\
\hline 5 & 1 & 1 & No & Suburban & $\begin{array}{l}\text { Local hospital } \\
\text { affiliated }\end{array}$ & 28 \\
\hline 6 & 3 & 5 & Yes & Suburban & Residency & 78 \\
\hline 7 & 4 & 6 & No & Urban & $\begin{array}{l}\text { Federally qualified } \\
\text { health center }\end{array}$ & 110 \\
\hline 8 & 1 & 1 & No & Suburban & Independent & 29 \\
\hline
\end{tabular}

PRINS-2, Primary Care Network Survey 2.

Chronic headaches were the third most common type of pain in the nonopioid group and second in the opioid group. More patients taking opioids had $\geq 3$ types of chronic pain documented in the chart than did those not taking opioids $(P=.04)$; the patients taking opioids were significantly more likely to have a mental health diagnosis $(P=.005)$ as determined by the reporting physician (Table 3 ).

\section{Assessment and Management of Patients Taking Chronic Opioids with Those Not Taking Opioids}

Patients taking opioids had significantly better chart documentation of their pain severity, functional disability, and psychological distress than did those not taking opioids (Table 4); however, documentation rates in general were low, with only $68 \%$ of all patients with CNMP having at least one documentation of pain severity, $41 \%$ of functional disability, and $32 \%$ of psychological or emotional distress from the pain. Those taking opioids were more likely to have been referred to a specialist (both pain and other specialists) than those not taking chronic opioids. However, similar numbers in both groups had reportedly used physical modalities such as physical therapy. $\mathrm{Pa}$ tients with CNMP generally used multiple medications for their pain, including both analgesics and adjunct medications such as muscle relaxers, antiepileptics, and sleeping aids. Those taking chronic opioids were more likely to use $\geq 5$ drugs for pain management $(40 \%$ vs $7 \% ; P<.001)$ and were much less likely to be using a single drug ( $3 \%$ vs $24 \% ; P<.001)$ than were those not taking opioids.

Table 2. Demographics of Participating Family Physicians and Medical Assistants

\begin{tabular}{lccc}
\hline Demographics & $\begin{array}{c}\text { Physicians Completing PRINS-2 } \\
(\mathrm{N}=21)\end{array}$ & $\begin{array}{c}\text { Physicians Interviewed } \\
(\mathrm{N}=10)\end{array}$ & $\begin{array}{c}\text { Medical Assistants/Nurses } \\
\text { Interviewed }\end{array}$ \\
\hline $\begin{array}{l}\text { Mean age (years) } \\
\text { Sex }\end{array}$ & 46 & 44 & 37 \\
$\quad$ Female & 38 & 30 & 100 \\
Male & 62 & 70 & 0 \\
Race & 80 & 70 & 70 \\
White & 5 & 10 & 30 \\
African & 15 & 20 & 0 \\
American & & & \\
Asian & & & \\
American & & & \\
\hline
\end{tabular}

Values provided as percentages unless otherwise indicated.

*Subset of 21 completing survey.

${ }^{\dagger}$ There were 8 medical assistants, 1 registered nurse and 1 licensed practical nurse.

PRINS-2, Primary Care Network Survey 2. 
Table 3. Comparison of Patients with Chronic Nonmalignant Pain by Chronic Opioid Use

\begin{tabular}{llcr}
\hline Patient Factor & Chronic Opioids $(\mathrm{N}=65)$ & No Chronic Opioids $(\mathrm{N}=72)$ & .78 .7 \\
\hline Mean age of patient (years) & 54.2 & 19.1 minute & .003 \\
Mean length of index office visit (min) & 17.9 minutes & 57 & .021 \\
Patient sex (female) & 55 & & $\mathrm{NS}$ \\
Patient race & & 80 & $\mathrm{NS}$ \\
$\quad$ White & 76 & 20 & .005 \\
African American & 24 & 44 & .04 \\
Patients with a mental health diagnosis & 69 & 13 & \\
Patients with $\geq 3$ types of pain & 26 & & \\
\hline
\end{tabular}

Values provided as percentages unless otherwise indicated.

NS, not significant.

\section{Physician and MA Interviews}

Difficulty with Prescribing Chronic Opioids for CNMP

Physicians described skepticism and suspicion of patients' motives as a primary difficulty with prescribing or considering chronic opioids when caring for patients with chronic pain. Eight of the 10 physicians mentioned some variation of this concern.

"I think there is a distrust, or a suspicion, because it is so easy for the patients to put on a show, so you don't really know if the pain is true or false."

"I guarantee you are going to run into the diverters, the people who are selling the stuff on the street."

"There is a subset of patients who are in chronic pain but are also chronic abusers or users of the system as far as narcotics, going from one physician to another.... It's definitely a group that will make you turn off from even prescribing medications or wanting to belp patients."
However, several of the physicians were acutely aware of these feelings toward patients with chronic pain who were taking opioids and actively sought to separate themselves from these thoughts as they dealt with patients.

"I really try to look at this as a fresh new patient. They have their own set of circumstances and trying to start fresh rather than, 'this is another drug-seeking patient that I have to deal with and another chronic pain patient.' So trying to go into every [visit] with an open mind and trying to give them the benefit of the doubt, because a lot of times we don't do that, we are just suspicious right off the bat."

Physicians rarely mentioned managing opioid side effects or dosing titration as significant problems. One physician described how he works with his patients to balance their need for opioids with their level of functioning: "I have to walk a fine line with him in terms of encouraging him to

Table 4. Assessment and Management of Patients Taking and Not Taking Opioids

\begin{tabular}{|c|c|c|c|}
\hline & Chronic Opioids $(\mathrm{N}=65)$ & No Chronic Opioids $(\mathrm{N}=72)$ & $P$ \\
\hline Level/amount of pain severity & 77 & 60 & .031 \\
\hline Level/amount of functional disability due to pain & 54 & 29 & .003 \\
\hline $\begin{array}{l}\text { Level/amount of psychological distress } \\
\text { (depression, anxiety, insomnia, etc) due to pain }\end{array}$ & 48 & 18 & $<.001$ \\
\hline $\begin{array}{l}\text { Presence of a second opinion from a specialist } \\
\text { (other than a pain specialist) to help diagnose } \\
\text { etiology of the pain or assist with diagnosis or } \\
\text { management }\end{array}$ & 66 & 38 & .001 \\
\hline $\begin{array}{l}\text { Presence of a second opinion from a pain } \\
\text { specialist to help diagnose etiology of the pain } \\
\text { or assist with management }\end{array}$ & 34 & 10 & .001 \\
\hline $\begin{array}{l}\text { Presence of current and/or past use of physical } \\
\text { modalities, such as physical therapy }\end{array}$ & 40 & 39 & NS \\
\hline
\end{tabular}

Values provided as percentages of patient charts with documentation of specific assessment or management noted at least once. NS, not significant. 
keep that level of function but be better at listening to his body. I keep a pretty tight rein on his escalations.”

\section{Office Teamwork When Managing Patients Taking Chronic Opioids}

There was little teamwork in these practices between physicians and MAs when caring for patients with CNMP who are taking chronic opioids. Several MAs noted that patients tell them things they will not tell the physician.

"When I'm in the room they'll tell me about street drugs and things like that, but when the doctor walks in, I know they are not going to tell him that, because they think 'he won't give me a prescription then."'

"Patients are more relaxed with me. Plus, I've known these people, a lot of them, for 10 years, so they will tell me all kinds of stuff."

Although most MAs tried to communicate this information to the physician, either in a note or informally before the visit, this did not always happen; as one MA acknowledged, "I will try to tell the doctor, but sometimes it does go unnoticed, because coming out of the door and making sure everything is charted and making sure everything is ready for the doctor, there just isn't time." None of the physician or MA participants reported a physician ever asking for an MA's opinion about a patient. There were few structured opportunities for face-to-face communications about patients taking chronic opioids; one practice had regular "huddles" before visits, during which such concerns would be raised, but most communication was informal or via patient notes or EMR flags and memos.

MA duties in caring for patients with CNMP on opioids generally related to taking a brief history, as noted above and performing "medication reconciliation." This process varied from simply asking patients if there were changes to a structured discussion of each prescribed medication. MAs also dealt with phone requests for refills of opioids from patients and pharmacies. Several MAs found that "one of the most difficult things is the phone calls....Patients with chronic pain will call significantly more and it's a handful."

\section{Methods for Improving Care of Patients with CNMP Who Are Taking Opioids}

Physicians suggested changes in care related to both monitoring of opioid use and enhancing patient care, most of which were similar to those found in national guidelines. ${ }^{32,33,36,37}$ These included performing urine drug screening (7 of 10 physician participants), instituting narcotic use contracts (5 of 10), setting strict opioid refill policies (6 of 10), and using state prescription reports to search for additional opioid use by patients (2 of 10). In addition, they described the importance of frequent, regular patient visits, patient education and self-management, and using both pain and subspecialty consultants. As one physician noted, "I would hope that $99.9 \%$ of my patients that are on long-term narcotics, that if you look in their chart, you would find a letter [from a consultant] saying that this is the treatment plan and you can do it." However, most physicians acknowledged that they were lax in meeting these goals: "We'll do a urine drug screen once a year. Are we doing that? Probably not. We're trying." In addition to simply forgetting, these activities were sometimes "low on the priority scale" for physicians dealing with patients with complex medical problems. Communication with patients around activities such as drug screens and narcotic contracts also was intimidating to some physicians. Many dealt with that issue by assuming a "universal precaution" stance where patients are told, "this is just our policy and what we do. And it's not just our policy, but the medical board recommends that it be done." One physician noted that, "I think when I initially start talking to them about contracts I was nervous about how people were going to respond, but it's kind of an interesting thing how people are, whether they're compliant or not, at least they pretend to be."

\section{Discussion}

Family physicians and other PCPs often find themselves in an uncertain situation when considering chronic opioids for patients with CNMP. The literature notes that "pain often goes undetected in the primary care encounter, and when acknowledged, is often undertreated." 4 At the same time, the literature also states that "increased opioid prescribing has paralleled increases in opioid misuse including overdoses, diversion, and addiction." ${ }^{16}$ Combined with new proposed and enacted laws regulating prescription of chronic opioids, ${ }^{30}$ PCPs are conflicted about prescribing opioids for chronic pain. ${ }^{15}$ Physicians in the CARinG Network expressed this internal conflict, being suspicious of patients' motives while still wanting to alleviate pain. Although many expressed a 
desire to follow accepted pain care guidelines, there was a disconnect between what these physicians believe is the best way to manage CNMP and the actual chart findings for patients with CNMP. Office teamwork and system-based care, as described in $\mathrm{PCMH}$ models, ${ }^{38}$ were rarely mentioned as methods to improve chronic pain care.

Patients with CNMP who are prescribed chronic opioids for their pain are in many ways different than patients with CNMP who do not receive opioids. In this study, they were younger, had more mental illness, had more types of pain, and used a greater number of medications for their pain. However, some studies in primary care settings have used the provision of opioids to define patients with CNMP. ${ }^{17,23}$ Other studies, including surveys of providers, lump all patients with CNMP together when asking about attitudes and behaviors. ${ }^{19,20}$ To better use the medical literature to guide future interventions in pain care, more research is needed to determine if the differences we found exist in other primary care practices and networks.

Family physicians in this study not only confirmed the well-documented discomfort with prescribing opioids for patients with CNMP,${ }^{19,20}$ they also described how it impacts them in a busy practice. Schiavenato and $\mathrm{Craig}^{39}$ posit that the assessment of pain in the clinical encounter is a social transaction with 5 steps: The patient's experience of pain is expressed by the patient, then assessed and judged by the physician, who then offers an intervention. All this occurs within a background of trust and scrutiny. Nicolaidis ${ }^{40}$ described 3 approaches that physicians take when considering opioids for chronic pain: (1) law enforcement (Is the pain real? Is the patient an addict or diverter?); (2) bargaining (How little opioid can I prescribe? Is the patient keeping his end of the agreement?); and (3) patient-centered benefit-to-harm ratio (Do the benefits of opioids outweigh their risks?). The physicians in this study described these social transactions and their difficulty in making decisions about opioids. Although many of the physicians described "law enforcement" and "bargaining" approaches (eg, "You don't really know if the pain is true or false" and "I educate them about what is expected"), several described how they sought to be patient centered with each patient with CNMP. Physicians described multiple approaches even with one patient. For example, the patient-centered physician who helped to educate his patient about "listening to his body" also "kept a pretty tight rein" over the patient's opioid dose, such that the patient had to "make a case" and bargain for a different dose.

Despite verbalizing a goal to incorporate many patient care and monitoring tools from guidelines and state laws, such as urine drug screening, narcotic use contracts, and state prescription reports, these were rarely documented in the patient charts. Patients taking chronic opioids were more likely to have pain, function, and psychological assessments in the chart and to have second opinions, but these were far from universal. The literature confirms that knowledge of guidelines alone does not change chronic pain practice. ${ }^{19,41}$ Rather, as these participants acknowledged, forgetfulness, lack of time, and competing demands-common issues long known in primary care-remain important barriers. ${ }^{19,42}$ However, in addition to finding better systems for implementing these tools in practice, some common guideline recommendations, such as urine drug screens, are being questioned, leading physicians to struggle with a changing knowledge base of how best to monitor patients taking chronic opioids. $^{14,15,43}$

Within the CARinG Network practices, chronic pain also was generally managed by the physician alone; MAs were delegated to monitoring refill requests and taking vital signs. In all but one practice, there was no structured time to discuss daily patient concerns. Even though several MAs noted that patients tell them things they might not tell the doctor, MAs did not always share this with physicians, and physicians rarely asked for the MAs' insights or opinions. Studies of successful chronic pain care programs in primary care often include a "team" approach. ${ }^{44}$ Although many of these team components are not readily available within most primary care practices (eg, behavioral counselors, social workers, physical therapists), a starting place would be to partner with MAs and work together to achieve practice goals for CNMP care. ${ }^{45,46}$ Teamwork between PCPs and office support staff like MAs has been shown to improve the quality of patient care and advance the PCMH model. ${ }^{45,47}$

There are limitations to this study. The CARinG Network is a relatively small PBRN located in one geographical region, and the practices are not necessarily representative of all practices in this region or in the country. Patients were defined as having chronic pain by their physician, and though all patients identified as such did have 
chronic pain documented in their chart, there is the possibility that other patients with CNMP were not flagged and were missed in the chart review. The chart review did not look at old charts or previous paper charts for those patients in practices with EMRs. However, all charts went back at least 2 years. This study also collected data only about processes of care, not outcomes. However, as previously noted, there is an evidence base that supports improved outcomes with many of these processes. ${ }^{32,33,37}$

\section{Conclusions}

Caring for patients with CNMP is a growing part of primary care, and whether to use chronic opioids for the pain is an ongoing concern for PCPs. ${ }^{2,11,19,20}$ We found that patients who were prescribed opioids had more complex pain syndromes, with more mental illness and more types of pain than those not taking opioids. These patients with CNMP who are taking chronic opioids also had significantly more assessments documented for pain, function, and psychological distress, a key recommendation of evidence-based practice guidelines for all patients with CNMP. ${ }^{32,33}$ These findings raise the importance of selection and description of patients with CNMP in primary care research. The physicians at the practices all desired higher-quality care for all their patients with CNMP and expressed a goal to practice evidencebased care for patients with chronic pain. As with other complex chronic diseases, patient management within the PCMH model, including teamwork, coordination, and integration of care; clinical decision support tools; patient self-management; and quality improvement, are potential solutions to improve care of patients with chronic pain. Further research will be necessary to tell whether incorporating more components of the PCMH will lead to improvement or whether new approaches are the key.

\section{References}

1. Manchikanti L, Benyamin R, Datta S, Vallejo R, Smith H. Opioids in chronic noncancer pain. Expert Rev Neurother 2010;10:775-89.

2. Institute of Medicine. Relieving pain in America. A blueprint for transforming prevention, care, education and research. Committee on Advancing Pain Research, Care, and Education. Washington, DC: National Academies Press; 2011. Available from: http://books.nap.edu/openbook.php?record_id = 13172 \&page $=\mathrm{R} 1$.
3. Clark JD. Chronic pain prevalence and analgesic prescribing in a general medical population. J Pain Symptom Manage 2002;23:131-7.

4. Gannon M, Qaseem A, Snow V, Snooks Q. Pain management and the primary care encounter. J Prim Care Community Health 2011;2:37-44.

5. Khouzam HR. Chronic pain and its management in primary care. South Med J 2000;93:946-52.

6. Moulin DE, Clark AJ, Speechley M, Morley-Forster PK. Chronic pain in Canada-prevalence, treatment, impact and the role of opioid analgesia. Pain Res Manag 2002;7:179-84.

7. Verhaak PFM, Kerssens JJ, Dekker J, Sorbi MJ, Bensing JM. Prevalence of chronic benign pain disorder among adults: a review of the literature. Pain 1998;77:231-9.

8. Wagner EH, Austin BT, Von Korff M. Organizing care for patients with chronic illness. Milbank Q 1996;74:511-44.

9. Clark LG, Upshur CC. Family medicine physicians' views of how to improve chronic pain management. J Am Board Fam Med 2007;20:479-82.

10. Olsen Y, Daumit GL. Opioid prescribing for chronic nonmalignant pain in primary care: challenges and solutions. Adv Psychosom Med 2004;25:138-50.

11. Potter M, Schafer S, Gonzalez-Mendez E, et al. Opioids for chronic nonmalignant pain. Attitudes and practices of primary care physicians in the UCSF/Stanford Collaborative Research Network. University of California, San Francisco. J Fam Pract 2001;50:145-51.

12. Bendtsen P, Hensing G, Ebeling C, Schedin A. What are the qualities of dilemmas experienced when prescribing opioids in general practice? Pain 1999;82:89-96.

13. Braden JB, Russo J, Fan MY, et al. Emergency department visits among recipients of chronic opioid therapy. Arch Intern Med 2010;170):1425-32.

14. Heit HA, Gourlay DL. Tackling the difficult problem of prescription opioid misuse. Ann Intern Med 2010;152:747-8.

15. Katz MH. Long-term opioid treatment of nonmalignant pain: a believer loses his faith. Arch Intern Med 2010;170:1422-4.

16. Liebschutz JM, Alford DP. Safe opioid prescribing: a long way to go. J Gen Intern Med 2011;26:951-2.

17. Ponte CD, Johnson-Tribino J. Attitudes and knowledge about pain: an assessment of West Virginia family physicians. Fam Med 2005;37:477-80.

18. Green CR, Wheeler JR, Marchant B, LaPorte F, Guerrero E. Analysis of the physician variable in pain management. Pain Med 2001;2:317-27. 
19. Leverence RR, Williams RL, Potter M, et al. Chronic non-cancer pain: a siren for primary care - a report from the PRImary care MultiEthnic Network (PRIME Net). J Am Board Fam Med 2011;24:551-61.

20. Upshur CC, Luckmann RS, Savageau JA. Primary care provider concerns about management of chronic pain in community clinic populations. J Gen Intern Med 2006;21:652-5.

21. Starrels JL, Becker WC, Weiner MG, Li X, Heo M, Turner BJ. Low use of opioid risk reduction strategies in primary care even for high risk patients with chronic pain. J Gen Intern Med 2011;26:958-64.

22. Gourlay DL, Heit HA, Almahrezi A. Universal precautions in pain medicine: A rational approach to the treatment of chronic pain. Pain Med 2005;6:107-12.

23. Osmun WE, Copeland J, Parr J, Boisvert L. Characteristics of chronic pain patients in a rural teaching practice. Can Fam Physician 2011;57:e436-40.

24. Butchart A, Kerr EA, Heisler M, Piette JD, Krein SL. Experience and management of chronic pain among patients with other complex chronic conditions. Clin J Pain 2009;25:293-8.

25. Hwang SW, Wilkins E, Chambers C, Estrabillo E, Berends J, Macdonald A. Chronic pain among homeless persons: characteristics, treatment, and barriers to management. BMC Fam Pract 2011;12:73.

26. Morasco BJ, Duckart JP, Dobscha SK. Adherence to clinical guidelines for opioid therapy for chronic pain in patients with substance use disorder. J Gen Intern Med 2011;26:965-71.

27. Crabtree B, Miller W. Doing Qualitative Research. 2nd Edition. Thousand Oaks, CA: Sage; 1999.

28. Mayan M. Introduction to Qualitative Methodology. Alberta: International Institute for Qualitative Methods; 2001.

29. Binns HJ, Lanier D, Pace WD, et al. Describing primary care encounters: the Primary Care Network Survey and the National Ambulatory Medical Care Survey. Ann Fam Med 2007;5:39-47.

30. Medscape. State-by-state opioid prescribing policies. Available from: http://www.medscape.com/ resource/opioid/opioid-policies. Accessed February 3, 2012.

31. University of Michigan Medical School. Managing chronic non-terminal pain including prescribing controlled substances. Ann Arbor: University of Michigan Health System. Available from: http:// cme.med.umich.edu/pdf/guideline/pain.pdf. Accessed July 12, 2012.

32. Institute for Clinical Systems Improvement. Health care guideline: assessment and management of chronic pain, fifth edition, November 2011. Available from: http://www.icsi.org/pain_chronic_assessment_and_ management_of_14399/pain_chronic_assessment_ and_management_of_guideline_.html. Accessed July 12, 2012.

33. Chou R, Fanciullo GJ, Fine PG, et al. Clinical guidelines for the use of chronic opioid therapy in chronic noncancer pain. J Pain 2009;10:113-30.

34. Miller M, Crabtree BF. Clinical research. A multimethod typology and qualitative roadmap. In: Crabtree BF, Miller M, eds. Doing Qualitative Research. 2nd ed. Thousand Oaks, CA: Sage; 1999.

35. Miller W, Crabtree BF. Qualitative analysis: how to begin making sense. Fam Pract Res J 1994;14:289-97.

36. Federation of State Medical Boards of the United States, Inc. model policy for the use of controlled substances for the treatment of pain. 2004. Available from: http://www.fsmb.org/pdf/2004_grpol_Controlled_Substances.pdf. Accessed February 2, 2012.

37. University of Michigan Medical School. Managing chronic non-terminal pain including prescribing controlled substances. Ann Arbor: University of Michigan Health System; 1-34. Available from: http://cme. med.umich.edu/pdf/guideline/pain.pdf. Accessed July 12, 2012.

38. Rosenthal TC. The medical home: growing evidence to support a new approach to primary care. J Am Board Fam Med 2008;21:427-40.

39. Schiavenato M, Craig KD. Pain assessment as a social transaction: beyond the "gold standard." Clin J Pain 2010;26:667-76.

40. Nicolaidis C. Police officer, deal-maker, or health care provider? Moving to a patient-centered framework for chronic opioid management. Pain Med 2011;12:890-7.

41. Gordon DB, Dahl JL. Quality improvement challenges in pain management. Pain 2004;107:1-4.

42. Stange KC, Zyzanski SJ, Jaen CR, et al. Illuminating the 'black box.' A description of 4454 patient visits to 138 family physicians. J Fam Pract 1998;46:377-89.

43. Gugelmann HM, Perrone J. Can prescription drug monitoring programs help limit opioid abuse? JAMA 2011;306:2258-9.

44. Dobscha SK, Corson K, Perrin NA, et al. Collaborative care for chronic pain in primary care: a cluster randomized trial. JAMA 2009;301:1242-52.

45. Crabtree BF, McDaniel RR, Nutting PA, Lanham HJ, Looney AJ, Miller WL. Closing the physicianstaff divide: a step toward creating the medical home. Fam Pract Manag 2008;15:20-4.

46. Bodenheimer T, Laing B. The Teamlet model of primary care. Ann Fam Med 2007;5:457-61.

47. Lanham HJ, McDaniel RR, Crabtree BF, et al. How improving practice relationships among clinicians and nonclinicians can improve quality in primary care. Jt Comm J Qual Patient Saf 2009;35:457-66. 